Vieira, M. H., Araujo, C. F. \& Sampaio, C. H. (2017). Unconscious thought theory and marketing: A novel perspective for new insights. Consumer Behavior Review, 1(1) 11-23.

ISSN: 25267884

Editor: Prof. Dr. Marconi Freitas da Costa

Avaliação: Double blind review

Email da revista: cbr@ufpe.br

Recebido: 21 de dezembro de 2016

Aceito: 31 de março de 2017

\title{
UNCONSCIOUS THOUGHT THEORY AND MARKETING: A NOVEL PERSPECTIVE FOR NEW INSIGHTS
}

\author{
Marcia Horowitz Vieira \\ Clecio Falcão Araujo \\ Claudio Hoffmann Sampaio
}

Marcia Horowitz Vieira is PhD Candidate in Management at Pontifícia Universidade Católica - Brazil. E-mail: marcia.horowitz@gmail.com. Clecio Falcão Araujo is PhD Candidate in Management at Pontifícia Universidade Católica do Rio Grande do Sul - PUC-RS. Portifícia Universidade Católica do Rio Grande do Sul - PUC-RS. E-mail: clecioa@bol.com.br. Claudio Hoffmann Sampaio is Professor of Marketing at Portifícia Universidade Católica do Rio Grande do Sul - PUC-RS. Email: csampaio@pucrs.br. This research was supported by the National Counsel of Technological and Scientific Development (CNPq) and by the Coordination for the Improvement of Higher Education Personnel (CAPES). The authors thank the reviewers for the comments for improving the article.

\begin{abstract}
The Unconscious Thought Theory (UTT), a theory about human thought, is able to bring a new perspective for the marketing field. Marketing researches appropriate from the conscious thought, which represents only $5 \%$ of our brain capacity. By the time UTT starts to be incorporated as a new lens for a wide range of marketing topics, the outcomes may bring important contributions and advances for the field. This article aims to better understand how marketing is using UTT in order to extent knowledge. The desk research procedure resulted in 6 categories relating UTT and marketing and show that there is an important gap related to the use of this theory as a new perspective for marketing well-explored issues.

Keywords: Unconscious thought, UTT, Marketing, Systematic review
\end{abstract}

Esta obra está licenciado com uma Licença Creative Commons Atribuição 4.0 Internacional.

\section{INTRODUCTION}

Marketing, as known by its definition, is considered an applied field of research.
Research in marketing, consequently, is expected to be broad in its nature and to bring new insights in order to enrich knowledge about the effects and consequences of 
marketing actions, developing theory, or even simply to upgrade the marketing practice (Lehmanet al., 2011).

It is possible to find in the today's literature of the field the interrelation of marketing topics together with other fields of studies such as psychology, anthropology and sociology. This exchange and marriage of knowledge is renewing findings and perspectives and, in the same time, broadening the marketing field with new lenses and possibilities (Wilkie \& Moore, 2003). Since then, marketing themes that are usually quite a lot explored as consumer behavior, decision process, product development and management strategies can now be studied and known by new perspectives.

One of these possible new lenses is the Unconscious Thought Theory (UTT). The UTT is considered a theory about thought, in other words, is a theory about the stronger and weaker points of the unconscious and conscious thought (Dijksterhuis \& Nordgren; 2006, Dijksterhuis \& Strick, 2016). It is adaptive to psychological issues that are related with thought, such as choice, decision making, attitude change, problem solving, creativity and others (Dijksterhuis \& Nordgren, 2006). Thereby, considering that most studies in the field make use of the conscious thought, responsible for only $5 \%$ of our brain capacity, researches when taking into account the unconscious thought, that is able to optimize complex decisions and creativity, would probably have surprising outcomes and the opening of little known world for inquiry.

Thus, based on the possibility of expanding knowledge and opening new perspectives for the marketing field, this study aims to understand how marketing is using UTT. Until this moment, there is no study found that focused on the effort to search for articles that united marketing topics and the UTT.

That way, this article is presented in the following order: first, the UTT is explored in more details - time line, main characteristics, and limitations - then the methodological procedure is explained by each of it steps. Third, the desk research results are shown presenting the studies that relate marketing and the UTT and, finally, the conclusions.

\section{THE UNCONSCIOUS THOUGHT THEORY}

The unconscious is an important part of the everyday life. Most of what we do are unconscious activities such as talk, read, learn different languages, brush the teeth or walk on the streets. When we think what to say we don't need to select consciously each word, but they simply appear in our minds (Dijksterhuis \& van Olden, 2006). It happens because our unconscious work nonstop during conversations looking for the appropriate vocabulary and feeding our conscious to help us to express ourselves. On the other side, when we are listening to someone, the process is quite similar. We don't need to analyze each word consciously because our unconscious is able to transform in ideas all the sounds said (Shanks, 2010). When we read is the same process, each symbol is transformed in ideas. It is now simple to understand why it is so hard to learn a new language: when we talk or read, it is our conscious that is working because our unconscious is not prepared to choose or analyze each word yet.

Furthermore, the unconscious thought is also able to recover remote associations between concepts (Zhonget al., 2008), tend to generate more consistent judgments (Nordgren \& Dijksterhuis, 2009), distribute the attention among a wide range of characteristics (Dijkstra et al., 2013) and increases the capacity to detect deceptions (Albrechtsen et al.,2009).

However, the literature points out that the combination of the conscious and unconscious thought is ideal in order to solve problems and situations effectively (Nordgren, Bos \& Dijksterhuis, 2011). By understanding that each mode of thought has its special characteristics, the marriage of both thoughts is the perfect match to generate better judgements, decisions, choices and enhance creativity.

The conscious thought (CT) is more effective when it is necessary to decide between alternatives that would vary among two or three attributes only, because this mode of thought is more precise. The unconscious thought (UT) is more appropriate to use when there are many attributes. UT is able to better organize information than CT, because CT does not take into account any quality or key factor (Bargh, 2011). 
In addition, there are two forms of UT: the intuition and the instinct. The intuition is closely related to perception, to everything we learn and experience during life. The instinct, however, represent our automatic reactions, some sense of opportunity, directly related to our primitive inclinations.

\section{What is Unconscious Thought Theory (UTT)}

The UTT is defined as a theory of thought, taking into consideration the stronger and weaker points of the CT and UT. This theory describes de context when individual rely on intuition, after some delay or time, rather than making decisions and judgements carefully and in a systematic way (Dijksterhuis \& Nordgren, 2006; Dijksterhuis \& Strick, 2016).

The theory is based on the idea that UT works "bottom-up" and is able to incorporate large quantity of information, whereas CT works "top-down" and its capacity is quite limited. One of the main principles of this theory is the fact that CT has a narrow capacity and it leads to the idea that CT results in poor decisions, and this hypothesis was already tested and confirmed in some experiments made by Dijksterhuis (2004) (Dijksterhuis \& van Olden, 2006).

\section{The UTT Emergence}

Studies involving UTT are relatively recent. However, it is possible to detect some discussion about the existence of the unconscious thought since the beginning of the $18^{\text {th }}$ century during the Age of Enlightenment. After that, Freud, during the $19^{\text {th }}$ century and the study of psychoanalysis has transformed a simple notion in a consistent set of ideas, theories and techniques and believed that the unconscious was a prison where all individual's traumas were incarcerated their way (Dijksterhuis \& Nordgren, 2006).

By the 1950's, some researchers tried to quantify the CT processing capacity together with the human body sensorial system including CT and UT combined. These studies demonstrated that the conscious capacity is very low compared to the whole sensorial system of the human body. In 1960's important changes happened when researchers established theoretical limits related to the automatic control of the human thought and behavior. During the 1970's, the concept of the automatic process - nonconscious - was applied for the first time and it was confirmed (Bargh, 2011).

In the early 80 's, it was possible to see some considerable advances about the thought automatization. Other complex forms of processes about perceptions were found - not demanding CT - and the Dual Process models were formulated. By the end of the 90's researches about consumer behavior using priming showed that this type of device would influence behavior, judgments and decisions in a nonconscious form (Nordgren et al., 2011)

The 21th century was crucial to the legitimation of the UTT. During 2000, studies confirmed the existence of unconscious processes and its similarities with the CT when related to a goal pursuit. In 2006, Dijksterhuis \& Nordgren (2006) published the first article specifically about UTT and the influence of UT. Until 2011, the UT concept had a slight advance related to studies about judgment decisionmaking (JDM) since the UTT emergence way (Dijksterhuis \& Nordgren, 2006). From then on, few studies have been published, essentially in marketing, matching this new perspective and important subjects of the field.

\section{UTT Main Characteristics}

By contrasting UTT with other related theories and models, it is possible to better understand some important characteristics of UTT and also appraise the features offered by this new perspective (Bos, Dijksterhuis \& van Baaren, 2011).

The dual process models, for example, assume that there are two different routes to constitute an impression (of an individual) or an attitude, and allow some degree of individual choice. In this process model, one of the routes is much more effortful than the other one, however a person who has the capacity and the motivation is usually successful (Dijksterhuis \& Nordgren, 2006).

In the UTT, it is possible to choose between the CT and UT or either no thought at all. In addition, there are three possible routes: a simple route, where no thought is required; an unconscious route, that takes time but is quite simple; and a conscious route, considered more 
complex (Waroquier et al., 2010). Besides that, UTT doesn't support the idea that effort is a good, because the CT, in some situations, doesn't generate the better results than UT and not keeping these efforts is a way of not using schemas way (Dijksterhuis \& Nordgren, 2006).

Furthermore, in contrast to other models that involve systems and not routes and that are, essentially, informative about decisions and judgements, the UTT approach differs by not assuming separate systems, but describes the features of two processes instead of two separate systems or modules (Chartrand \& Fitzsimons, 2011). Another important characteristic of this theory is that it is seen as an active, generative and creative way of thinking. Some systems and models support that an associative system is passive and reproductive.

The UTT differ from other theories and models in a variety of aspects, however the most valuable contribution of this theory is the idea of the existence and benefits of the unconscious thought way (Dijksterhuis \& Nordgren, 2006).

\section{The Six Principles of UTT}

Moreover, the UTT is based in six main principles related to UT and CT: Unconscious Thought principle; the capacity principle; the bottom up versus top down principle; the weighting principle; the rule principle and the convergence versus divergence principle way (Dijksterhuis \& Nordgren, 2006).

The Unconscious Thought principle supports that CT and UT have different characteristics and each mode of thought is more appropriate to specific situations. In this principle, attention is considered the key to differ CT and UT, since CT needs attention and UT deviates attention to another activity way (Dijksterhuis \& Nordgren, 2006). The capacity principle says that the CT is affected by its low capacity. It can save, temporarily, only seven items what take to poor decisions and choices. Besides that, CT is only able to make less precise assessments and its focus is limited in relation to attributes (Wilson \& Schooler, 1991). The bottom-up x top-down principle is based on Sloman (1996) that argues that the thought processes are hierarchical, or happens from the top to the bottom, while automatic thoughts are the opposite. This principle consists in the idea that the UT works bottom up and reveals values integrating information in order to constitute precise judgements and CT works top down and build values guided by expectations and schemas (Nordgren et al., 2011). Besides, it supports the idea that stereotypes are formed by triggered in an automatic way and people are not conscious about it. In addition, this principle says that UT take a better organization in individual's memory and is motivated by goal pursuit way (Waroquier et al., 2010)

The weighting principle is based in the idea that UT is able to weight the importance of several attributes, while CT, generally, weights in a less precise way because it is not it's natural process of work. Nevertheless, the quality of these decisions is a subjective issue, since CT could make it better. In the other hand, CT weights in a disproportional way when considering accessible and easy attributes, depending on its complexity (Wilson \& Shooler, 1991). The rule principle supports that CT follows strict and precise rules, what is ideal in moments of taking decisions, while UT could only estimate and does not follow rules (Dijksterhuis \& Nordgren, 2006). Finally, the convergence versus divergence principle is considered more relevant in cases of creativity than in taking decisions or judgements, since the creativity is directly linked to the notion of incubation, when the unconscious activity keeps working if the conscious attention is directed to another place. So, this principle considers UT as offering divergent thoughts, motivating creativity and problem solving while there is distraction (Dijksterhuis \& Meurs, 2006).

\section{METHODOLOGICAL PROCEDURES}

The Grounded Theory is a general methodology of analysis related to data pursuit that uses a systematically applied method aiming to generate a inductive theory about a specific area (Glaser \& Strauss, 1967; Glaser, 1992). Although its rigor to create new theories, the methodology based on the Grounded Theory also provides the possibility to assess specific literature fields offering a robust and systematic way of review (Wolfswinkel, Furtmueller, Wilderom, 2013). One of the main advantages in adopting this approach is that it has an interactive nature as it enables the 
researcher to consult and return to the data collected in order to verify its meaning. The methodology based on the grounded theory is not limited to specific sources (Strauss \& Corbin, 1990). Thus, the present study is based on secondary data (journal articles) and, in order to reach these data, Moher et al. (2009) procedures were used, through the PRISMA protocol (Preferred Reporting Items for Systematic reviews and Meta-Analyses), besides Wolfswinkel et al. (2013) propositions. In addition, data search was divided in: (1) data collection and (2) data analysis by codification process.

\section{Systematic Review}

Following the established purpose of this article and understand how the marketing field is approaching the Unconscious Thought Theory, a desk research methodology was adopted, as the researcher is involved in the analysis of secondary data. The data collected in the present research aimed to analyze the literature around the Unconscious Thought Theory related to marketing issues that were published in journals since the seminal article of Dijksterhuis et al. (2006).

The procedures used were divided in the following steps: (1) register and criterion protocol, (2) information resources definition, (3) data collection process and (4) inclusion and exclusion criterion. The main intention of this research process was to exhaust the search space of all possible references about UTT and marketing. Thus, it is possible to infer that the data resources and research terms used in this study are representative in relation to the universe of the given theory.

To reach this goal, some filters were established. The first decision was to search for these articles in three of most considered databases: ISI Web of Knowledge, ProQuest and Google Scholar. A second decision was to filter the articles by the top marketing journals; however, it was not possible because the use of UTT spread publication through other fields of study such as psychology. Thus, this filter was made based on the journal's impact factor classification: $H$-Index $>1$ journals were considered. The third decision was to search for the last 10 years publications, since UTT started to boom by 2006. By the end, the keywords used for this search were "marketing" and "unconscious thought theory" or "UTT" and the selection of the articles were made through the analysis of its title, keywords and summary.

The ISI Web of Knowledge database, considering all the filters established, using the keyword "unconscious thought theory" showed a total of 347 articles in the last 10 years. When the second keyword "marketing" was applied, the total of articles relation the two expressions was 4 article only. In the ProQuest database, the same procedure was adopted and a total of zero articles appeared. Finally, in the google scholar database, when applied the same filters and actions the results was 17.100 articles.

In order to make it more specific and effective, a search for the seminal article about UTT called "The Theory of Unconscious Thought" by Dijksterhuis and Nordgren (2006) was made. After that, it was verified a large number of citations (total of 760). Then, the decision was to click on the articles that have cited this seminal about UTT and filter with the keyword "marketing", keeping the search in the 10 last years.

The results then showed 134 articles. After that, each one of these studies were analyzed separately, considering: a) the journal impact factor based on the H-Index, and the total number of articles decreased to 34 ; b) the existence of a marketing subject being studied (some articles would appear in this search only because there were any marketing word insert, such as the authors' descriptions or a marketing reference used) and c) the use of UTT in the study of a marketing theme. By the end, from the last four articles from ISI Web of knowledge, none could be considered and the total and final number of articles selected were 14, all from the Google Scholar database.

Through the desk research, it was already possible to confirm the fact that the marketing field is not appropriating from the UTT as much as it could, characterizing the theoretical gap that support the purpose of the present study.

\section{Categorization}

After the data collection step and articles refinement, the title, abstract and passages of the literature review of the analyzed studies relating UTT to marketing topics were extracted. This data was then submitted to 
content analysis procedures proposed by the Grounded Theory principles, according Wolfswinkel et al. (2013). In the categorization step, codification was made in parallel by two researchers. As a result, the following main categories were formed: Decision Process; Choice; Consumer Behavior; Product development and creativity; Judgement and Information overload.

\section{MARKETING AND UTT}

The academic activities in the marketing field was formally constituted about 100 years ago. Society and academy have been going through massive changes during all this years (Wilkie \& Moore, 2003). Even though, a wealthy body of marketing literature has been enriched and expanded. However, what's the focus of today's academic field of marketing? What can this field of study bring as novelty to the academy and to the society? Are researches looking for new perspectives?

The answers for all these questions are still to come. Today's academic field of marketing is still too focused in studying firms' aspects and consumer behavior. Nevertheless, a few scope of researchers is luckily considering and developing research in marketing in a broadened and new perspective, aggregating new insights and theories, and building relationships with other fields of study and the society (Anderson, 1983; Shaw \& Jones, 2005; Wilkie \& Moore, 2003).

Based on the desk research made in order to better understand how marketing is using the UTT, a new perspective for the field, it was possible to observe that the articles are concentrated in the psychology field, what explains it's closeness to the investigation of people's behavior. As previously defined, the 6 main categories relation UTT and marketing are presented as follows.

\section{Decision Process}

During the search for studies in marketing that would integrate the UTT, it was evident the great variety of articles approaching the decision making process. However, after that application of the established filters, only four from the 14 studies found would relate to marketing using UTT.
In 2009 Nordgren, and Dijksterhuis found, after 5 experiments, that deliberation would reduce consumer's preferences consistency, in other words, the individuals who did not deliberate according to their preferences, involved in a decision process, were more consistent compared to the ones who did it (Nordgren \& Dijksterhuis, 2009). Besides that, the authors conclude that the weighting of information in a decision process is negatively affected by deliberation, leading to inconsistency, when complex information is involved.

One year later, in the same line of study of the previous authors, Bos, Dijksterhuisand van Baaren (2011) tested and then confirmed the assumption that UT head to an automatic weighting process in decision processes. What they mean is that important decision attributes have more weight and less important attributes get lower weight during a decision (Bos et al., 2011). After three experiments, they confirm the hypothesis that UT actually leads to an automatic weighting process. In the same year, Bentzen et al. (2011) turn the attention to the organizational decision process, especially on how managers focus their attention as decision makers.

The article slightly approach the idea that CT is better when considering making linear and analytical decisions, while UT is more effective on solving complex situations (Zhong et al., 2008) and also takes to a higher level of satisfaction after making a decision (Dijksterhuis \& van Olden, 2006). Despite the fact that the authors highlight that attention of decision makers is crucial when considering complex problems and situation, this study does not use in its analysis the UTT in order to reach its outcomes. It shows that marketing researchers were aware of the possible benefits of the use of UTT to their object of study.

Eling et al. (2014) in their study named "Using Intuition in Fuzzy Front-End DecisionMaking: A Conceptual Framework", developed a conceptual framework to better understand why and under which conditions the use of intuition in the decision making process of a new product development would or would not be beneficial in terms of creativity (Eling et al., 2014). By the end, the authors infer that intuition use may bring benefits to making and evaluating decisions during the creative 
process. It was justified by the fact that intuition derives from an UT, which leads to special capabilities. However, this result is not applicable to all situations, since the authors understand that the UT could not be adequate to specific occasions when, for example, precision insights are required.

When considering decision processes and UTT, the desk research showed that despite the fact that this theme is widely approached by other fields of study such as psychology; the marketing field is not exploring this combination as it could. The explored themes are concentrated in weighting attributes in decision process (2 articles); managers attention focus as decision makers, but not considering UTT directly and the benefits of using intuition. Table 1 summarizes what was found in this section.

Table 1

Summary of Decision Process and UTT articles

\begin{tabular}{|c|c|c|c|c|}
\hline $\begin{array}{l}\text { Article } \\
\end{array}$ & Journal & Year & Author & Marketing Issue \\
\hline $\begin{array}{l}\text { The Devil Is in the Deliberation: } \\
\text { Thinking Too Much Reduces } \\
\text { Preference Consistency }\end{array}$ & $\begin{array}{l}\text { Journal of } \\
\text { Consumer } \\
\text { Research }\end{array}$ & 2009 & $\begin{array}{l}\text { Nordgren, L. } \\
\text { Dijksterhuis, A. }\end{array}$ & $\begin{array}{l}\text { Preferences consistency } \\
\text { choice, decision making }\end{array}$ \\
\hline $\begin{array}{l}\text { The benefits of "sleepingonthings": } \\
\text { Unconscious thought leads to } \\
\text { automatic weighting }\end{array}$ & $\begin{array}{l}\text { Journal of } \\
\text { Consumer } \\
\text { Psychology } \\
\end{array}$ & 2011 & $\begin{array}{l}\text { Bos, M. } \\
\text { Dijksterhuis, A. } \\
\text { van Baaren, R. } \\
\end{array}$ & $\begin{array}{l}\text { Decision process } \\
\text { weighting process }\end{array}$ \\
\hline $\begin{array}{l}\text { What attracts decision makers' } \\
\text { attention?: Managerial allocation of } \\
\text { time at product development } \\
\text { portifolio meeting }\end{array}$ & $\begin{array}{l}\text { Management } \\
\text { Decision }\end{array}$ & 2011 & $\begin{array}{l}\text { Bentzen, E. } \\
\text { Christiansen, J. } \\
\text { Vames, C. }\end{array}$ & $\begin{array}{l}\text { Decision making } \\
\text { (organization) }\end{array}$ \\
\hline $\begin{array}{l}\text { Using Intuition in Fuzzy Front-End } \\
\text { Decision-Making: A Conceptual } \\
\text { Framework }\end{array}$ & $\begin{array}{l}\text { Journal of } \\
\text { Product } \\
\text { Innovation } \\
\text { Management }\end{array}$ & 2014 & $\begin{array}{l}\text { Eling, K. } \\
\text { Griffin, A. } \\
\text { Langerak, F. }\end{array}$ & $\begin{array}{l}\text { Decision making, } \\
\text { Product develop, } \\
\text { Creativity }\end{array}$ \\
\hline
\end{tabular}

Source: Prepared by the authors

\section{Choice}

This marketing theme could be find in 4 of the 14 articles selected. It was also possible to verify that it involves other themes approaches such as choice/rejection; quality of choice; customization and preferences consistency.

By 2006, right after that seminal article about UTT was published; Dijksterhuis and van Olden presented a study comparing the CT and the UT in relation to the quality of choice. Based on a previous study of Dijksterhuis (2004) that showed that individuals make better choices when engaging in UT (using distraction) then in CT. In this study, then, the authors decides to better consider the quality of decision in real alternatives, and the quality of each choice could be measured by the post-choice satisfaction of the participant (Dijksterhuis \& van Olden, 2006; Dijksterhuis, 2004). The findings showed that participants in the UT condition were more satisfied about their choice compared to the others.

Some years later, Nordgren and Dijksterhuis (2009) besides approaching the decision process theme, these authors also consider that deliberation would take to inconsistency when weighting complex information, especially. The last two experiments found that deliberation also affects, negatively, preference consistency the degree to which individuals maintain their preferences after a period - according to the complexity of information (Nordgren \& Dijksterhuis, 2009). It means that deliberation, depending on the information type, can decrease preference consistency leading individuals to regret their choices.

A couple years after, Van Osselaer and Janiszewski (2012) in their article, "A GoalBased Model of Product Evaluation and Choice" propose a model related to product evaluation and choice processes, adding information about goal-based product assessment and choice processes; offering a new theory involving goal activation and product evaluation and choices processes and building predictions (van Osselaer \& Janiszewski, 2012). The authors explore the debates about the benefits of engaging in a CT or UT when combining and weighting complex information about 
evaluations and choices (Dijksterhuis \& van Olden, 2006). They infer that decision processes frame the goal-based choice model, and that it offers better capacity to weight information (UT) than decision strategies that would not be able to consider multiple attributes (CT). The attributes weighting is appearing as an explored subject relating marketing and UTT and it can fit in a variety of contexts as decision process and choice or others.

One of the most recent articles linking the UTT and a marketing topic is the study of Laran, Janiszewski and Salerno (2016). In this article the authors approach the idea that during conscious or unconscious thought modes an individual is able to be aware or not about an active goal in the moment of making a choice.
Being aware (CT) enables individuals to identify relevant attributes related to their goal evaluate the efficacy of each feature related to each specific alternative (Laran et al., 2016). Engaging in this process could lead to the most consistent choice to the established goal or also unleash a competing goal that could lead to a goal inconsistent choice. Whereas, being unaware (UT) leads to the selection of the attributes that match with the active goal, it does not mean that this alternative is the most effective to achieve the goal. This article also could be linked with the weighting issue, when UT is not able to assess efficacy of features of the available choices, but can combine goals and attributes. Table 2 demonstrated the articles found about this topic related to UTT.

Table 2

Summary of Choice and UTT articles

\begin{tabular}{|l|c|c|c|c|}
\hline \multicolumn{1}{|c}{ Article } & \multicolumn{1}{c|}{ Journal } & Author & Marketing Issue \\
\hline $\begin{array}{l}\text { On the benefits of thinking } \\
\text { unconsciously: Unconscious } \\
\text { thought can increase post-choice } \\
\text { satisfaction. }\end{array}$ & $\begin{array}{c}\text { Journal of } \\
\text { Experimental } \\
\text { Social Psychology }\end{array}$ & 2006 & $\begin{array}{c}\text { Quality of choice, } \\
\text { vhoice making, } \\
\text { satisfaction }\end{array}$ \\
\hline $\begin{array}{l}\text { The Devil Is in the Deliberation: } \\
\text { Thinking Too Much Reduces } \\
\text { Preference Consistency }\end{array}$ & $\begin{array}{l}\text { Journal of } \\
\text { Consumer } \\
\text { Research }\end{array}$ & 2009 & $\begin{array}{c}\text { Nordgren, L. } \\
\text { Dijksterhuis, A. }\end{array}$ & $\begin{array}{c}\text { Preferences } \\
\text { consistency choice, } \\
\text { decision making }\end{array}$ \\
\hline $\begin{array}{l}\text { Goal-Based Model of Product } \\
\text { Evaluation and Choice. }\end{array}$ & $\begin{array}{l}\text { Journal of } \\
\text { Consumer } \\
\text { Research }\end{array}$ & 2012 & $\begin{array}{c}\text { van Osselaer, S. } \\
\text { Janiszewski, C. }\end{array}$ & $\begin{array}{c}\text { Product evaluation, } \\
\text { choice making }\end{array}$ \\
\hline $\begin{array}{l}\text { Exploring the differences } \\
\text { between conscious and } \\
\text { unconscious goal pursuit }\end{array}$ & $\begin{array}{l}\text { Journal of } \\
\text { Marketing } \\
\text { Research }\end{array}$ & 2016 & $\begin{array}{c}\text { Laran, J. } \\
\text { Saniszewski, C. } \\
\text { Salerno, A. }\end{array}$ & Choice making \\
\hline
\end{tabular}

Source: Prepared by the authors

\section{Consumer behavior}

In this section, all articles were published in a row. It means that the 3 articles that fit in this marketing subject were published in the year of 2011. Martin and Morich (2011), based on evidences about unconscious behavior, propose a model about consumer behavior that integrates conscious and unconscious mental processes in order to demonstrate the way consumers make brand decisions in a real daily life context. This model is supported by the idea that theories of consumer behavior use to point that individuals are rational and conscious about their decisions when purchasing specific brands products or services (Martin \& Morich, 2011).

Furthermore, the literature in marketing and consumer behavior use to support that consumer previously constituted attitudes and need determine what brand consumers would choose. This article highlights a new research perspective originated from the automaticity proposes that state that almost all-human behavior begins as an unconscious process or occurs totally without conscious. The article is from 2011, and brought two relevant marketing topics (consumer behavior and branding) together with the UTT perspective.

In the same year and in the maintaining the same line of study, Woodside et al. (2011) explored the role of unconscious consumer behavior in branding contexts, considering the same issues as the previous article when taking into account the power of UT compared to CT in individuals behavior, especially related to deciding and choosing products and brands. The great contribution of this article would be a 
call to study more about unconscious together with consumer/brand behavior, reactions and beliefs (Woodside \& Brasel, 2011).

Still in 2011, Chartrand and Fitzsimons studied about consumption behavior and the unconscious process. The authors, supported by the literature, believed that individuals enter in a consumption behavior without perceiving the effect of unconscious process on their decisions and life in general (Chartrand \& Fitzsimons, 2011). It means that there are several environmental triggers of consumption behavior that consumers are unaware, and also can lead to not desired outcomes (Chartrand, 2005). The article also detaches the idea of increasing knowledge by advancing unconscious process studies related to consumer behavior.

Consumer behavior field seems to be a potential field to advance and develop its several issues with the use of the unconscious thought lens. Table 3 shows a summary of what was found relating consumer behavior and UTT.

Table 3

Summary of Consumer Behavior and UTT articles

\begin{tabular}{|l|c|c|c|c|}
\hline \multicolumn{2}{|c|}{ Article } & Journal & Year & Author \\
\hline $\begin{array}{l}\text { Unconscious metal processes in } \\
\text { consumer choice: Toward a new } \\
\text { model of consumer behavior }\end{array}$ & $\begin{array}{c}\text { Journal of Brand } \\
\text { Management } \\
\text { Morich, K. }\end{array}$ & 2011 & $\begin{array}{c}\text { Consumer behavior, } \\
\text { Branding }\end{array}$ \\
\hline $\begin{array}{l}\text { Nonconscious Consumer } \\
\text { Psychology }\end{array}$ & $\begin{array}{c}\text { Journal of } \\
\text { Consumer } \\
\text { Psychology }\end{array}$ & 2011 & $\begin{array}{c}\text { Chartrand, T. } \\
\text { Fitzsimons, G. }\end{array}$ & Consumer behavior \\
\hline $\begin{array}{l}\text { Unconscious thinking, feeling and } \\
\text { behavior toward products and } \\
\text { brands: Introduction to a Journal } \\
\text { of Brand Management }\end{array}$ & $\begin{array}{c}\text { Journal of Brand } \\
\text { Management }\end{array}$ & 2011 & $\begin{array}{c}\text { Woodside, A. } \\
\text { Brasel, S. }\end{array}$ & $\begin{array}{c}\text { Consumer behavior } \\
\text { Branding }\end{array}$ \\
\hline
\end{tabular}

Source: Prepared by the authors

\section{Product development and Creativity}

Product development and creativity are important aspects for the marketing field and 2 articles were found related to these themes. In the UTT literature, creativity is considered to be facilitated by UT, called divergent thinking (Dijksterhuis \& Meurs, 2006). It can be explained by the fact that CT uses specific rules and generates responses that do not diverge from the expected pattern. But when someone is engaged in UT (and is distracted from the problem to solve), their thoughts would be less likely to be close to fixed patterns, besides the fact that UT is able to uncover remote associations (Zhong et al., 2008).

Yang et al. (2012) through their article named "Unconscious creativity: When can unconscious thought outperform conscious thought?" also support the idea about UT's superiority, demonstrating that UT has an inverted-U relationship with creativity performance. It concludes that during short or long period of deliberation, UT is unlikely to offer creative advantages (Yang et al., 2012). Nevertheless, when deliberation is moderate in duration, UT leads to better outcomes. The authors highlight the contribution of their study stating the power and limits of UT and detach the importance of some adjustments when using UT in order to stimulate creativity.

In 2014, Eling et al., as mentioned previously, approached in their research the intuition role in decision making and product development creativity. The authors ascertained about the strict theoretical sources to explain the benefits of intuition in generating creativity, and developed a conceptual framework in order to increase knowledge about the theme and fill the theoretical gap found (Eling et al., 2014). The outputs showed that intuition tend to be beneficial to making and evaluating decisions during creative processes due to the unconscious capabilities, but not in all kinds of contexts. In addition, the authors believe that research could advance based on the framework presented in order to better understand the intuition roles and effects in decision-making processes and creativity. Table 4 show the summary of the articles found about the topic. 
Table 4

Summary of Product development and creativity and UTT articles

\begin{tabular}{|l|c|c|c|c|}
\hline \multicolumn{1}{|c|}{ Article } & \multicolumn{1}{c|}{ Journal } & \multicolumn{2}{c|}{ Author } & Marketing Issue \\
\hline $\begin{array}{l}\text { Unconscious creativity: When } \\
\text { can unconscious thought } \\
\text { outperform conscious thought? }\end{array}$ & $\begin{array}{c}\text { Journal of } \\
\text { Consumer } \\
\text { Psychology }\end{array}$ & 2012 & $\begin{array}{c}\text { Chattopadhay, A. } \\
\text { Zhang, K. } \\
\text { Dhal, D }\end{array}$ & $\begin{array}{c}\text { Product develop, } \\
\text { Creativity }\end{array}$ \\
\hline $\begin{array}{l}\text { Using Intuition in Fuzzy Front- } \\
\text { End Decision-Making: A } \\
\text { Conceptual Framework }\end{array}$ & $\begin{array}{c}\text { Journal of } \\
\text { Product } \\
\text { Innovation } \\
\text { Management }\end{array}$ & 2014 & $\begin{array}{c}\text { Eling, K. } \\
\text { Griffin, A. } \\
\text { Langerak, F. }\end{array}$ & $\begin{array}{c}\text { Decision making, } \\
\text { Product develop, } \\
\text { Creativity }\end{array}$ \\
\hline
\end{tabular}

Source: Prepared by the authors

\section{Judgment}

In this section, only one article was selected. There is a slight line between some subjects of marketing and psychology as both could approach behavior, but in different ways.

In 2013, Dijkstra and colleagues asked what produces better judgments: deliberating or relying on intuition? Until that moment, they argued that the literature was inconclusive and could not answer. Then, the authors hypothesized that a person who have experience but does not have much knowledge about a subject should suffer from deliberation and benefit from intuition - they don't have formal knowledge to understand their preferences (Dijkstra et al., 2013).
In addition, individual who have good or bad knowledge and experience should do well and poorly, in this same order, no matter the decision mode. Results of the 3 experiments showed that the individual who had experience and no formal knowledge actually performed better when using intuition and the judgments of experienced and not experienced were not affected, and also that the outcomes confirmed the what is in the literature: the effect of the processing mode on quality of judgment is moderated by the expertise. Table 5 demonstrates what was found for judgment and UTT.

Table 5

Summary of Judgment and UTT articles

\begin{tabular}{|c|c|c|c|c|}
\hline Article & Journal & Year & Author & Marketing Issue \\
\hline $\begin{array}{l}\text { Deliberation Versus Intuition: } \\
\text { Decomposing the Role of } \\
\text { Expertise }\end{array}$ & $\begin{array}{c}\text { Journal of } \\
\text { Behavioral } \\
\text { Decision Making, }\end{array}$ & 2013 & $\begin{array}{c}\text { Dijkstra, K. } \\
\text { van der Pligt, J. van } \\
\text { Kleef, G. }\end{array}$ & Judgments \\
\hline
\end{tabular}

Source: Prepared by the authors

\section{Information overload}

The information overload can be considered a current marketing topic as globalization; internet and social networks are generating, ceaselessly, new information. This much of information can cause a series of effects on consumer's life and decisions (Gao et al., 2012; Messner \& Wänke, 2011). After the desk research, even being a quite potential issue, it was found only 2 articles relating information overload and UTT.

In 2011, Messner and Wänke reinforce the idea that consumers tend to be less satisfied with their choice when are exposed to a large assortment than when they need to choose to a limited one. The overload of information can lead to a decrease in satisfaction about the choice made, while reducing overload would enhance satisfaction (Messner \& Wänke, 2011). Based on UTT, the authors conclude that this logic reverses when consumers do not have to deliberate. When consumers are distracted, even exposed to wide assortment of the product tended to present higher product satisfaction. The article contributes to better understanding how UTT can add by exploring current situation using a new perspective. The UT is able to better deal with more information and choices then $\mathrm{CT}$, what benefits the information overload contexts.

At last, Gao et al. (2012), in their article titled as "Understanding online purchase decision making: The effects of unconscious thought, information quality, and information quantity", 
showed a current reality related to the fact that consumers may not have the capacity to process all the available information because our conscious is too limited (Gao et al., 2012). They highlight the situation with online shoppers, who are exposed to a giant amount of information every day and are not able to process everything properly.

Differently to the previous studies, the authors propose a new perspective to the information overload considering the UT, integrating UTT and the formation process theory, taking into account information quantity, information quality and the thought mode in consumers. The outputs of this interesting study showed that UT moderates the relationship between the information quality and the satisfaction of the consumer in relation to decision making, when shopping online.

This article, in special, demonstrates exactly what the marketing field need: the integration of UTT and marketing theme in order to find new solutions and outcomes. The authors still stand out that the article contribution involves UTT and information processing theory, by integrating the effect of information quantity and quality and the thought mode (CT or UT) influencing in the quality of purchasing decisions (Gao et al., 2012). Table 6 shows the articles found matching UTT and information overload.

Table 6

Summary of Information overload and UTT articles

\begin{tabular}{|l|c|c|c|c|}
\hline \multicolumn{1}{|c|}{ Article } & Journal & Year & Author & Marketing Issue \\
\hline $\begin{array}{l}\text { Unconscious information processing reduces } \\
\text { information over load and increases product } \\
\text { satisfaction. }\end{array}$ & $\begin{array}{l}\text { Journal of } \\
\text { Consumer } \\
\text { Psychology }\end{array}$ & 2011 & $\begin{array}{c}\text { Messner, C. } \\
\text { Wänke, M. }\end{array}$ & Information overload \\
\hline $\begin{array}{l}\text { Understanding online purchase decision } \\
\text { making: The effects of unconscious thought, } \\
\text { information quality, and information } \\
\text { quantity }\end{array}$ & $\begin{array}{l}\text { Decision } \\
\text { Support } \\
\text { Systems }\end{array}$ & 2012 & $\begin{array}{c}\text { Gao, J. } \\
\text { Zhang, C. } \\
\text { Wang, K. } \\
\text { Ba, S. }\end{array}$ & $\begin{array}{c}\text { Online shopping } \\
\text { Information quantity } \\
\text { Information quality } \\
\text { Information overload }\end{array}$ \\
\hline
\end{tabular}

Source: Prepared by the authors

\section{CONCLUSIONS}

This article aimed to better understand how the marketing field is using UTT in its researches. The results showed what was expected: the marketing field is still not appropriating from UTT in order to advance knowledge and uncover new perspectives as other fields of studies - such as psychology and information systems - have been doing.

The Unconscious Thought is an intuitive process that generates approximate responses, warranting better decisions when the alternatives of choice are constituted by various attributes. Besides that, the UT is able to weight and integrate information in order to optimize decision-making, organizing it in an effective way and separating ideas in different clusters. Still, this mode of thought facilitates creativity (divergent thinking) and works very well with complex decisions and contexts. All this characteristics enable a variety of marketing subjects to bring new insights and outcomes, when used in an integrative way.
The UTT, in turn, is a thought theory and enhances the positive and negative aspects of both thoughts modes: conscious and unconscious. It means that, depending on the context, a specific thought mode fits better. UTT is usually applied for psychological phenomenon associated with thought, such as choice, decision making, problem solving and creativity.

After the desk research, which considered articles that related marketing topics that used UTT in journals with significant impact factor during the last 10 years. The application of the filters established resulted in only 14 articles that would cover all the requisites. From these 14 articles, 4 of them could fit in the decision process theme, approaching subjects such as information weighting and organizational decision process; other 4 were classified to the choice section, approaching about quality of choice and preference consistency. Other 3 were about consumer behavior, approaching online shopping, branding and consumption behavior; 
2 about product development and creativity, approaching topics such as product development creativity and evaluation; 1 approached judgment and 2 fit in the information overload topic, approaching relevant subjects such as information quality and quantity.

The main contribution of this mapping about marketing and UTT is the confirmation of the fact that the marketing field and the marketing researches are underspending the possibility of advance knowledge and uncover new insights and discoveries by integrating marketing subjects and the UTT.

Even considering that, UTT is still an incipient theory and has its limitations and criticisms to overcome - such as how UT transfers knowledge and information to CT and the presentation of more evidences that prove the UT existence effectively - the marketing field could develop research in order to contribute to the UTT evolution and, in special, to marketing topics growth.

\section{REFERENCES}

Albrechtsen, J. S., Meissner, C. A. \& Susa, K. J. (2009). Can intuition improve deceptiondetection performance? Journal of Experimental Social Psychology, 45(4), 1052-1055.

Anderson, P. F. (1983). Marketing, scientific progress, \& scientific Method. Journal of Marketing, 47(4), 18-31.

Bargh, J. A. (2011). Unconscious thought theory and its discontents: A critique of the critiques. Social Cognition, 29(6), 629-647.

Bentzen, E., Christiansen, J. K. \& Varnes, C. J. (2011). What attracts decision makers' attention? Managerial allocation of time at product development portfolio meetings. Management Decision, 49(3), 330-349.

Bos, M. W., Dijksterhuis, A. \& van Baaren, R. B. (2011). The benefits of "sleeping on things": Unconscious thought leads to automatic weighting. Journal of Consumer Psychology, 21(1), 4-8.

Chartrand, T. L. (2005). The role of conscious awareness in consumer behavior. Journal of Consumer Psychology, 15(3), 203-210.

Chartrand, T. L. \& Fitzsimons, G. J. (2011). Nonconscious consumer psychology. Journal of Consumer Psychology, 21(1), 1-3.

Dijksterhuis, A. (2004). Think different: The merits of unconscious thought in preference development \& decision making. Journal of
Personality and Social Psychology, 87(5), 586598.

Dijksterhuis, A. \& Nordgren, L. F. (2006). A theory of unconscious thought. Perspectives on Psychological science, 1(2), 95-109.

Dijksterhuis, A. \& Meurs, T. (2006). Where creativity resides: The generative power of unconscious thought. Consciousness and Cognition, 15(1), 135-146.

Dijksterhuis, A., \& van Olden, Z. (2006). On the benefits of thinking unconsciously: Unconscious thought can increase post-choice satisfaction. Journal of Experimental Social Psychology, 42(5), 627-631.

Dijksterhuis, A. \& Strick, M. (2016). A case for thinking without consciousness. Perspectives on Psychological Science, 11(1), 117-132.

Dijkstra, K. A., Pligt, J. \& Kleef, G. A. (2013). Deliberation versus intuition: Decomposingthe role of expertise in judgment and decision making. Journal of Behavioral Decision Making, 26(3), 285-294.

Eling, K., Griffin, A. \& Langerak, F. (2014). Using intuition in fuzzy front-end decision-making: A conceptual framework. Journal of Product Innovation Management, 31(5), 956-972.

Gao, J., Zhang, C., Wang, K. \& Ba, S. (2012). Understanding online purchase decision making: The effects of unconscious thought, information quality, and information quantity. Decision Support Systems, 53(4), 772-781.

Glaser, B., \& Strauss, A. (1967). The discovery of grounded theory. Weidenfield \& Nicolson, London.

Glaser, B. G. (1992). Emergencevs forcing: Basics of grounded theory analysis. Sociology Press.

Laran, J., Janiszewski, C. \& Salerno, A. (2016). Exploring the differences between conscious and unconscious goal pursuit. Journal of Marketing Research, 53(3), 442-458.

Lehmann, D. R., McAlister, L. \& Staelin, R. (2011). Sophistication in research in marketing. Journal of Marketing, 75(4), 155165.

Martin, N. \& Morich, K. (2011). Unconscious mental processes in consumerchoice: Toward a new model of consumer behavior. Journal of Brand Management, 18(7), 483-505.

Messner, C. \& Wänke, M. (2011). Unconscious information processing reduces information overload and increases product satisfaction. Journal of Consumer Psychology, 21(1), 9-13.

Moher, D., Liberati, A., Tetzlaff, J., \& Altman, D. G. (2009). Preferred reporting items for systematic reviews and meta-analyses: The 
PRISMA statement. Annals of Internal Medicine, 151(4), 264-269.

Nordgren, L. F., Bos, M. W. \& Dijksterhuis, A. (2011). The best of both worlds: Integrating conscious and unconscious thought best solves complex decisions. Journal of Experimental Social Psychology, 47(2), 509-511.

Nordgren, L. F. \& Dijksterhuis, A. (2009). The devil is in the deliberation: Thinking too much reduces preference consistency. Journal of Consumer Research, 36(1), 39-46.

Shanks, D. R. (2010). Learning: From association to cognition. Annual Review of Psychology, 61, 273-301.

Shaw, E. H. \& Jones, D. B. (2005). A history of schools of marketing thought. Marketing Theory, 5(3), 239-281.

Sloman, S. A. (1996). The empirical case for two systems of reasoning. Psychological Bulletin, $119(1), 3$.

Strauss, A., \& Corbin, J. M. (1990). Basics of qualitative research: Grounded theory procedures and techniques. Sage Publications, Inc.

Van Osselaer, S. M. \& Janiszewski, C. (2012). A goalbased model of product evaluation and choice. Journal of Consumer Research,39(2), 260-292.

Waroquier, L., Marchiori, D., Klein, O. \& Cleeremans, A. (2010). Is it better to think unconscious lyor to trust your first impression? A reassessment of unconscious thought theory.
Social Psychological and Personality Science, 1(2), 111-118.

Wilkie, W. L. \& Moore, E. S. (2003). Scholarly research in marketing: Exploring the "4 eras" of thought development. Journal of Public Policy and Marketing, 22(2), 116-146.

Wilson, T. D. \& Schooler, J. W. (1991). Thinking too much: Introspection can reduce the quality of preferences and decisions. Journal of Personality and Social Psychology, 60(2), 181192.

Woodside, A. G. \& Brasel, S. A. (2011). Unconscious thinking, feeling and behavior toward products and brands: Introduction to a Journal of Brand Management special issue. Journal of Brand Management, 18(7), 451-456.

Yang, H., Chattopadhyay, A., Zhang, K. \& Dahl, D. W. (2012). Unconscious creativity: When can unconscious thoughtout perform conscious thought? Journal of Consumer Psychology, 22(4), 573-581.

Zhong, C. B., Dijksterhuis, A. \& Galinsky, A. D. (2008). The merits of unconscious thought in creativity. Psychological Science, 19(9), 912918.

Wolfswinkel, J. F., Furtmueller, E., \& Wilderom, C. P. (2013). Using grounded theory as a method for rigorously reviewing literature. European Journal of Information Systems, 22(1), 45-55. 